\title{
Middle Palaeolithic human dispersal in Central Asia: new archaeological investigations in the Orkhon Valley, Mongolia
}

Arina M. Khatsenovich ${ }^{1, *}$, Evgeny P. Rybin ${ }^{1}$, Dashzeveg Bazargur ${ }^{2}$, Daria V. Marchenko ${ }^{1}$, Sergei A. Kogai ${ }^{3}$, Tatiana A. Shevchenko ${ }^{4}$, Alexei M. Klementiev ${ }^{5}$, Byambaa Gunchinsuren ${ }^{2} \&$ John W. Olsen $^{6}$

Well-stratified Middle Palaeolithic assemblages are extremely rare in Mongolia. Initially investigated between the 1960s and 1990s, three major Middle Palaeolithic sites in the Orkhon Valley of central Mongolia yielded a large quantity of data and generated many research questions that still await answers. Re-investigation of these sites has uncovered chronostratigraphic and cultural sequences that may shed new light on human dispersal routes.

Keywords: Central Asia, Mongolia, Middle Palaeolithic, OSL, lithics

According to current perspectives on the routes of ancient human dispersal in Eurasia during the Middle and Late Pleistocene, migration corridors were palaeoclimatically homogeneous regions. Palaeolakes and freshwater arteries defined exit routes from Africa through the Arabian Peninsula, ultimately traversing South Asian rainforests farther to the east (Roberts et al. 2015; Dennell 2017). Eastern Central Asia is the current focus of much research because this territory was a contact area between Western Eurasian and Eastern Asian geographic and cultural macro-regions. One prehistoric migration route has been identified in eastern Central Asia, following the course of one of the region's principal fluvial arteries-the Selenga River Basin. During the Late Pleistocene (c. 50 000-12 000 years ago), this area witnessed the movement of early humans between northern Mongolia and Transbaikalia in southern Siberia, following the tributaries of the Selenga River and exploiting primary raw material outcrops along the way. Another possible earlier corridor is located in the Orkhon-Selenga mountain zone. Three stratified Palaeolithic sites in that zone-Orkhon-1, Orkhon-7 and

1 Institute of Archaeology and Ethnography of the Siberian Branch of the Russian Academy of Sciences, 17 Ac. Lavrentiev Avenue, Novosibirsk 630090, Russia

2 Institute of History and Archaeology MAS, 77 Zhukov Street, Ulaanbaatar, Mongolia

3 Irkutsk State University, 8 Lenina Street, Irkutsk 664025, Russia

4 Novosibirsk State University, 1 Pirogova Street, Novosibirsk 630090, Russia

5 Institute of the Earth's Crust SB RAS, 128 Lermontova Street, Irkutsk 664033, Russia

6 School of Anthropology, University of Arizona, East South Campus Drive, Tucson AZ 85721, USA

* Author for correspondence (Email: archeomongolia@gmail.com) 
Moil'tyn-am-have yielded the longest cultural and stratigraphic sequences anywhere in Mongolia, including both Middle Palaeolithic and Upper Palaeolithic materials (Figure 1). A project, aimed initially at re-dating these three localities, began in 2018 with the re-excavation of the Moil'tyn-am and Orkhon-1 sites.

The Moil'tyn-am site is located in central Mongolia near the modern settlement of Kharkhorin, on the second terrace of the Orkhon River. This site has been excavated on three previous occasions: in the 1960s and 1980s by a joint Soviet-Mongolian expedition and by a French-Mongolian team in 1996-1997. Only two chronometric dates are currently available for Moil'tyn-am: 20 240 300 BP (Gif-10857) from layer 4 (Bertran et al. 2003) in a test pit excavated by J. Jaubert during the 1990s field season, and 18 830 890 BP (SOAN-8156) from the Russian-Mongolian expedition's sondage. Based on excavations conducted in 1985-1986, the Moil'tyn-am cultural sequence contains Levallois components in horizons 2, 3 and 4 (Derevianko et al. 2010), and, together with the lithology of the artefacts, suggests that the typological character of the lithic assemblages is not clearly chronologically correlated. Thus, Moil'tyn-am is probably a palimpsest of human activity. New radiocarbon dates, supplemented by OSL determinations and micromorphological analyses, will help clarify this complex situation.

Recent excavation was directed towards the acquisition of samples for new OSL and radiocarbon determinations, analysis of the spatial distribution of artefacts within the site layers and re-thinking the Middle Palaeolithic Levallois technology of the assemblages. We identified undisturbed areas on the edge of the terrace, including a convenient location to excavate a $2 \times 1 \mathrm{~m}$ test pit. The sediment stack exposed here, containing more than 450 artefacts, is approximately $1.7 \mathrm{~m}$ in depth. We have preliminarily identified six lithological layers (Figure 2). The deposits of layers $2-4$ are deformed along one vertical line, which is probably the result of cryogenic processes.

Layers 2 and 3 are the most archaeologically rich, but artefacts were also recovered from layers 4 and 5, albeit at lower densities. Layer 6 was not identified by previous excavators and contained only two flakes. The lithic assemblage from layer 2 contains a retouched Levallois point with a chapeau de gendarme striking platform, and layer 3 has yielded a triangular retouched Levallois point, both produced by convergent unidirectional flaking — a technique widespread in the final Middle Palaeolithic and initial Upper Palaeolithic periods of Mongolia. Levallois flakes produced by the most common Middle Palaeolithic centripetal Levallois method were found in layer 4 (Figure 3). This cultural sequence, which will be dated by a series of OSL and radiocarbon assays, will support the long-term presence of Levallois technology in Mongolia, perhaps dated as late as $30550 \pm 410$ (AA-31870) at Chikhen-2 in the Gobi Altai region (Derevianko et al. 2015). Alternatively, it may suggest a palimpsest of cultural remains and the problematic nature of the chronological boundaries of Levallois technology in that region. This investigation also provides an opportunity to accumulate data on the human occupation of this area during the Last Glacial Maximum.

Another important site-Orkhon-1—was excavated in 2018 to determine the stratigraphic position of the Middle Palaeolithic cultural horizon and obtain samples for chronometric dating. A $3 \times 2 \mathrm{~m}$ sondage approximately $5 \mathrm{~m}$ deep yielded only a small archaeological assemblage, but was sufficient to identify an Upper Palaeolithic horizon in layer 4 and a single Middle Palaeolithic horizon in layer 7 (Figure 4). It was previously thought that this Middle (C) Antiquity Publications Ltd, 2019 


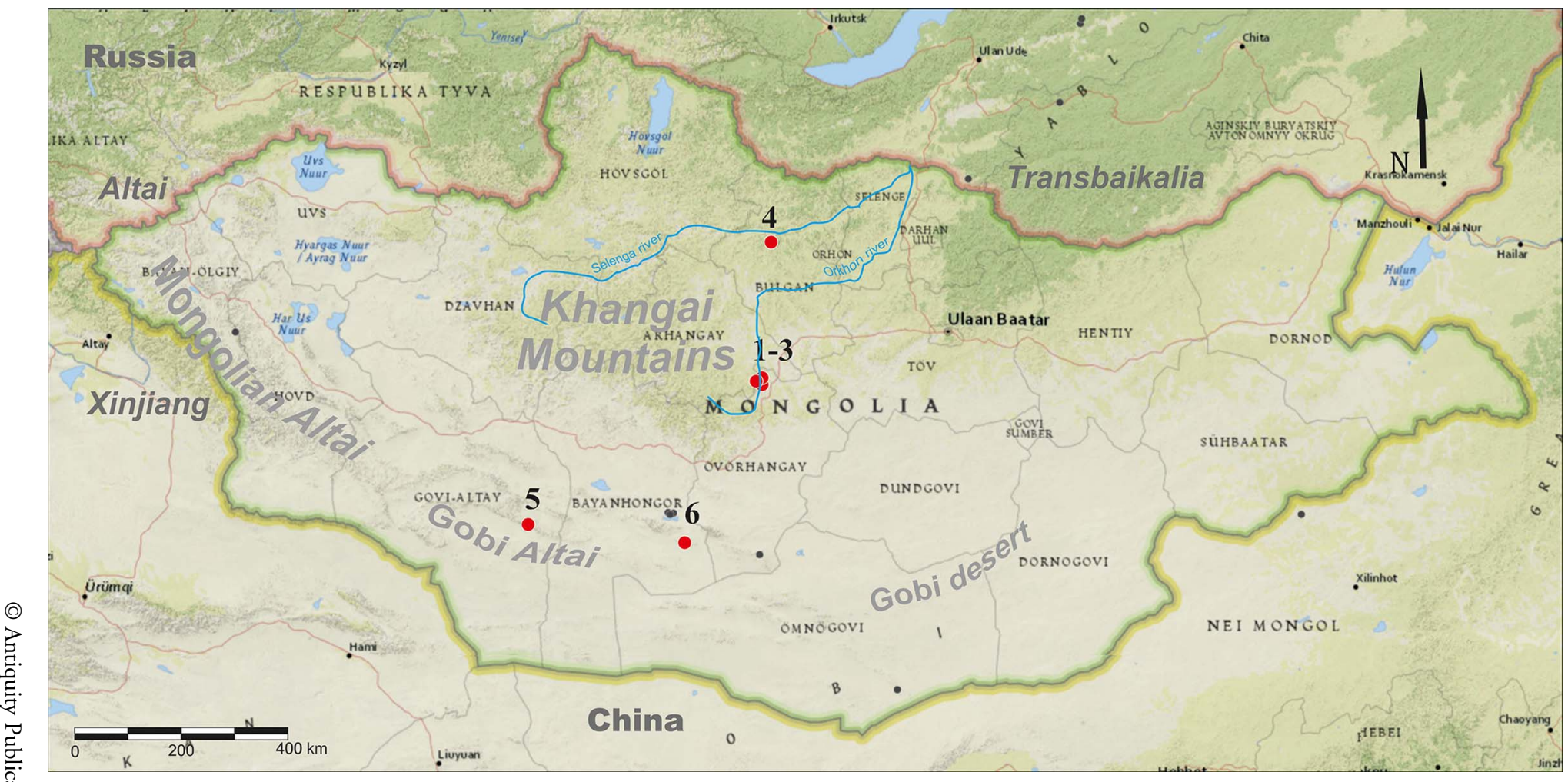

Figure 1. Map of sites with Middle Palaeolithic complexes in Mongolia: 1) Moil'tyn-am;2) Orkhon-1;3) Orkhon-7; 4) Kharganyn Gol 5; 5) Chikhen-2; 6) Tsagaan Agui Cave 5 (map produced using National Geographic Society Basemap and ArcGIS Online by Arina Khatsenovich). 


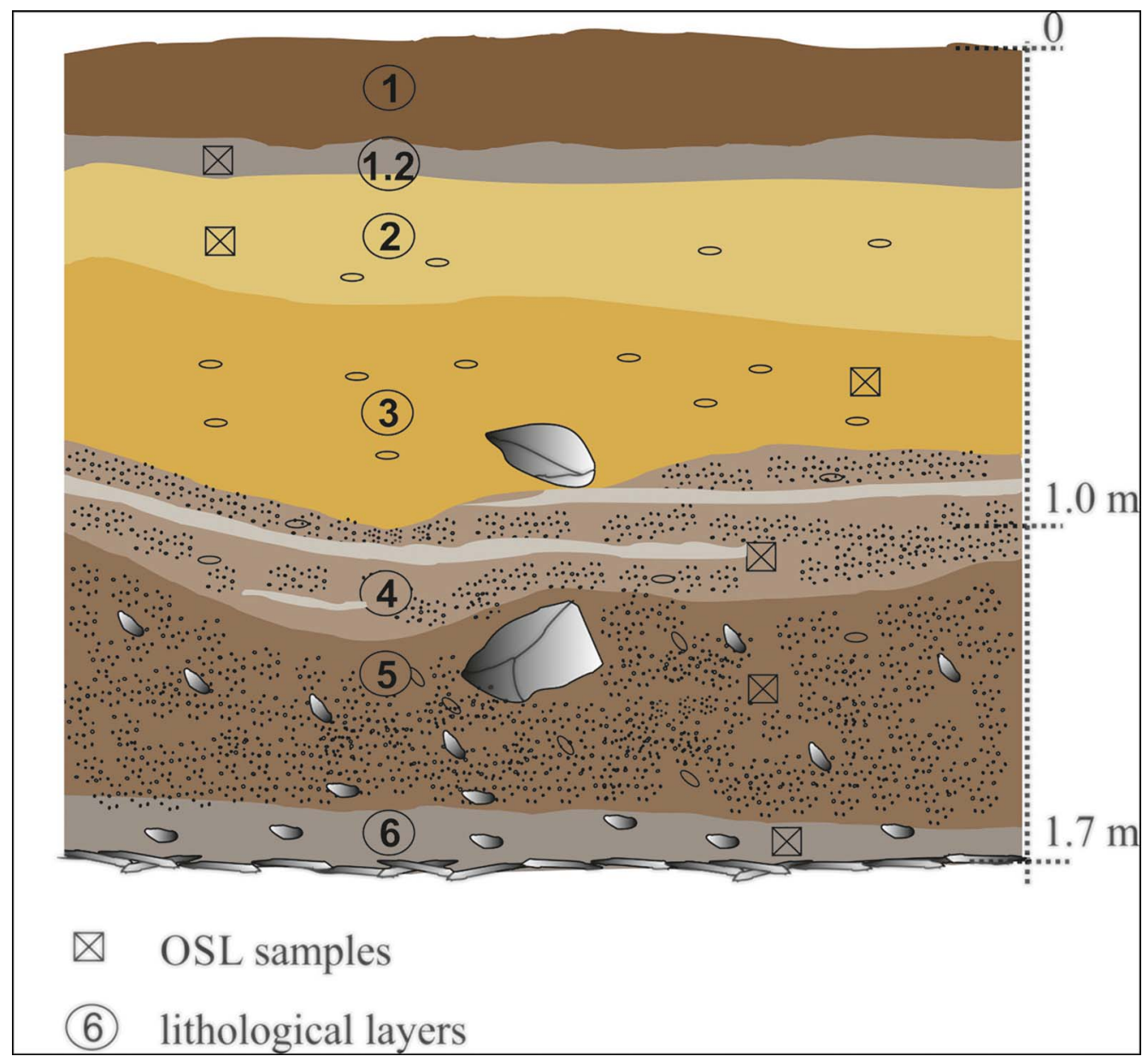

Figure 2. North-east-facing profile of the 2018 Moil'tyn-am test pit (figure by Arina Khatsenovich).

Palaeolithic material was derived from layer 6. In the absence of datable organic material, this horizon was assumed to be earlier than the top of the dated, archaeologically sterile, overlying layer 5, e.g. $38600 \pm 800$ BP (RIDDLE-716) (Derevianko et al. 2010).

Layer 7 is at the level of the ancient floodplain of the Orkhon River-the earliest stage of the second fluvial terrace, correlated with cold and arid conditions, profound cryogenic processes and a high degree of carbonisation. Taking into account the position of the Middle Palaeolithic horizon in layer 7, we cannot exclude the possibility that this occupational episode may have occurred around the time of Heinrich Event 5 (c. 45000 years ago (Hemming 2004)) or even earlier. This horizon includes a typical Middle Palaeolithic flake industry with Levallois technology (Figure 5). The 2018 lithic assemblage was also associated with bone samples that allow radiometric dating and exploration of the site's faunal complex. The mandible of an extinct Baikal yak, Bos (Poephagus) baikalensis, was recovered from the Middle Palaeolithic horizon. It is important to note that this is the first reliable reported discovery of a Bos baikalensis mandible with dentition.

(C) Antiquity Publications Ltd, 2019 
Middle Palaeolithic human dispersal in Central Asia

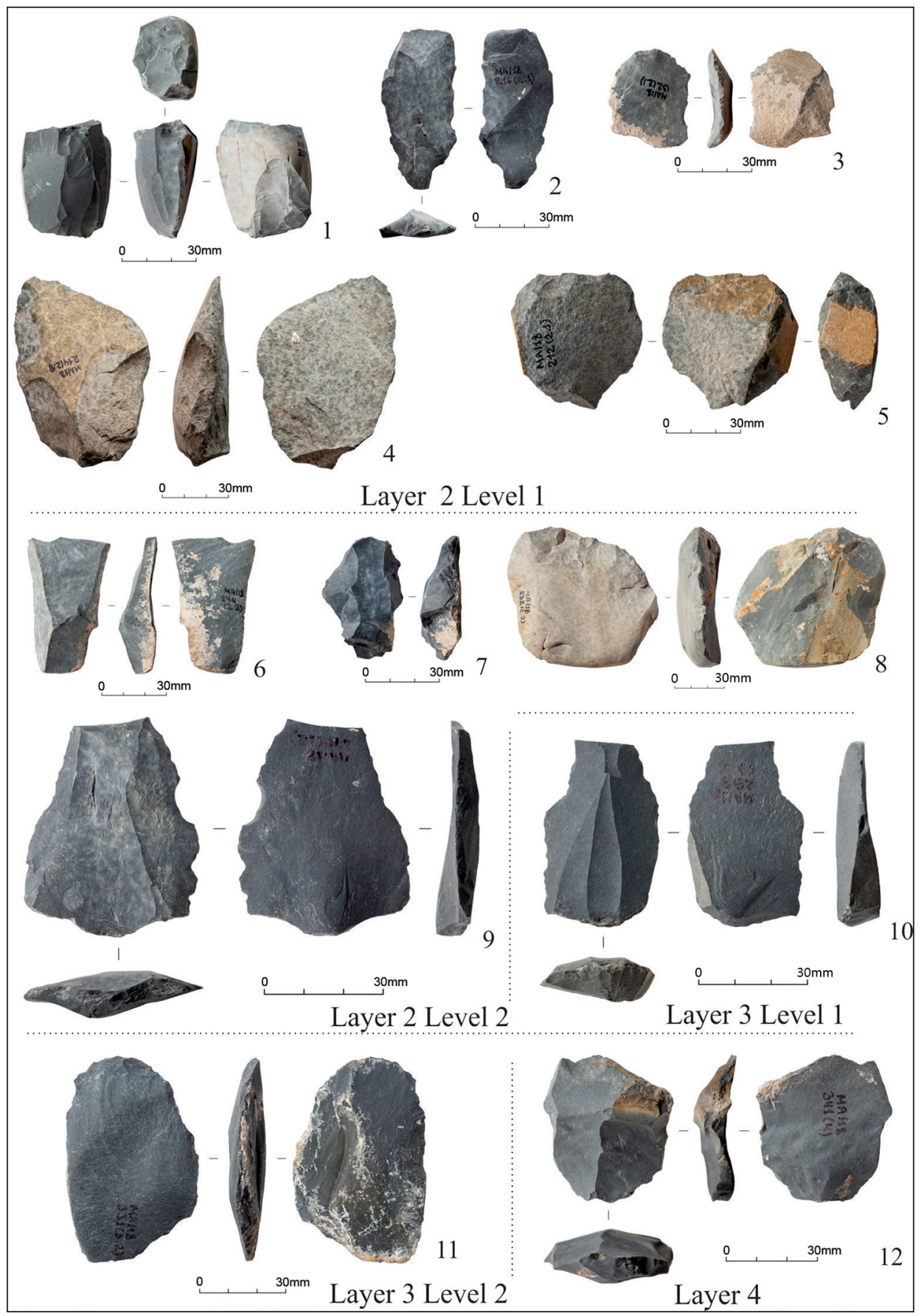

Figure 3. Moil'tyn-am, artefacts from layers 2-4: 1) sub-prismatic core; 2) stemmed blade; 3) perforator with ventral trimming; 4) dejété scraper; 5) end-scraper; 6) large bidirectional blade; 7) end-scraper; 8) bifacial scraper; 9-10) Levallois points; 11) side-scraper; 12) Levallois flake (fgure by Sergei Kogai). 


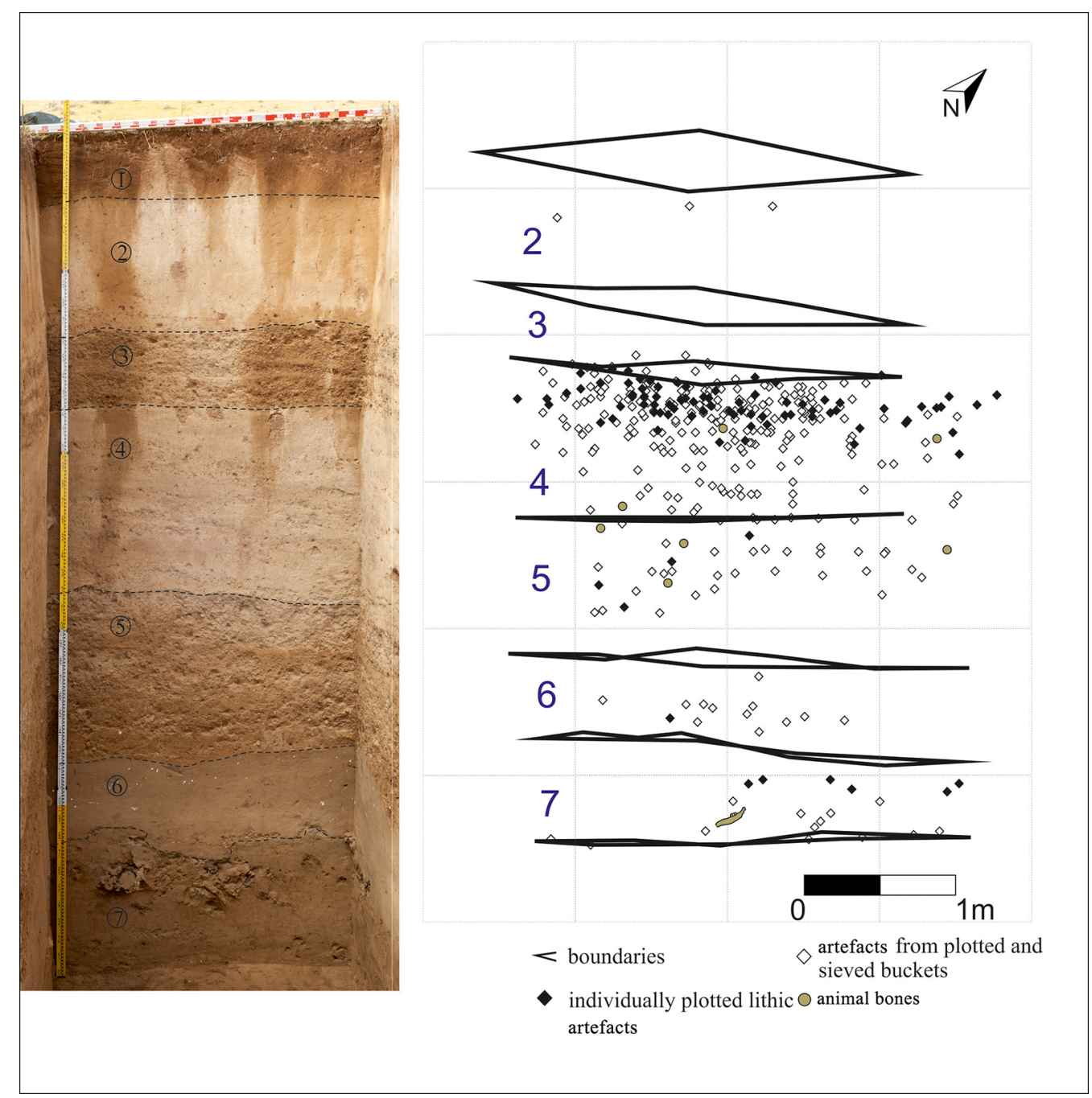

Figure 4. Orkhon-1, south-east-facing profile and spatial distribution of artefacts and faunal remains (figure by Daria Marchenko).

These sites are crucial for the reconstruction of Mongolia's Middle Palaeolithic cultural chronological sequence. Thus far, the Middle Palaeolithic in Mongolia is not associated with any reliable chronometric dates, except at Kharganyn Gol 5 in northern Mongolia, which is one of only six known stratified Middle Palaeolithic sites in the entire country. Radiocarbon dates for the Orkhon cluster of sites were generated in the 1980s, but their stratigraphic position and association with cultural materials are not clear (Derevianko et al. 2010). The new investigations described here are targeted at addressing the following research question: do we have evidence of frequent, episodic short-term occupations or diachronic cultural continuity? The Late Pleistocene was characterised by positive, ameliorating palaeoclimatic conditions and corollary landscape changes. It is important for archaeologists (C) Antiquity Publications Ltd, 2019 


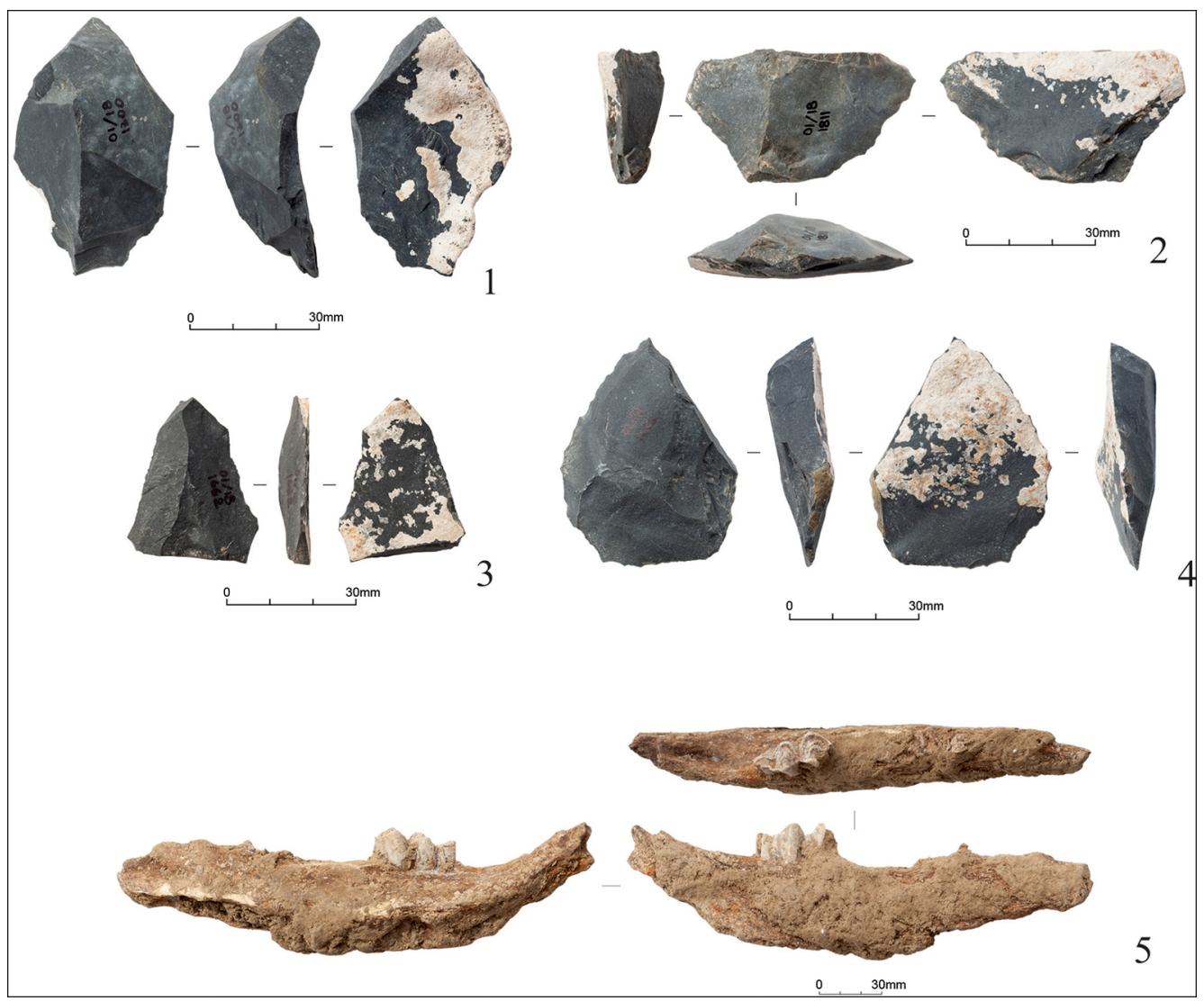

Figure 5. Orkhon-1, artefacts and faunal remains from layer 7: 1) core treatment element; 2) flake; 3) Levallois point; 4) point; 5) mandible of B. baikalensis (fgure by Sergei Kogai).

to determine how these factors contributed, individually and synergistically, to the opening of migration corridors. This raises the question for future research: during what period did a Middle Palaeolithic corridor function and where can we draw the chronological boundary between the latest Middle Palaeolithic complexes and the earliest Upper Palaeolithic assemblages in this region?

\section{References}

Bertran, P., M. Fontugne \& J. Jaubert. 2003. Permafrost aggradation followed by brutal degradation during the upper Pleniglacial in Mongolia: the probable response to the $\mathrm{H} 2$ Heinrich event at $21 \mathrm{kyr}$ BP. Permafrost and Periglacial Processes 14: 1-9. https://doi.org/10.1002/ppp.435

Dennell, R. 2017. Human colonization of Asia in the Late Pleistocene. Current Anthropology 47: 383-96. https://doi.org/10.1086/694174
Derevianko, A.P., A.V. Kandyba \& V.T. Petrin. 2010. Paleolithic of Orkhon. Novosibirsk: Institute of Archaeology and Ethnography SB RAS.

Derevianko, A.P., S.V. Markin, S.A. Gladyshev \& J.W. Olsen. 2015. The early Upper Paleolithic of the Gobi Altai region in Mongolia (based on materials from the Chikhen-2 site). Archaeology, Ethnology and Anthropology of Eurasia 3: 17-41. https://doi.org/10.1016/j.aeae.2015.11.004

Hemming, S.R. 2004. Heinrich events: massive Late Pleistocene detritus layers of the North Atlantic and their global climate imprint. Review of

(C) Antiquity Publications Ltd, 2019 
Geophysics 42: RG1005.

https://doi.org/10.1029/2003RG000128

Roberts, P., N. Perera, O. Wedage,

S. Deraniyagala, J. Perera, S. Eregama,

A. Gledhill, M.D. Petraglia \&
J.A. Lee-Thorp. 2015. Direct evidence for human reliance on rainforest resources in Late Pleistocene Sri Lanka. Science 347: 1246-49.

https://doi.org/10.1126/science.aaa1230

Received: 16 December 2018; Revised: 3 March 2019; Accepted: 12 April 2019

(C) Antiquity Publications Ltd, 2019 